\title{
FLEXIBILIZAÇÃO DO TRABALHO DOCENTE EM SÃO PAULO: PRECARIZAÇÃO E INSTABILIDADE
}

\section{EASING OF TEACHING IN SÃO PAULO: INSECURITY AND INSTABILITY}

\author{
Mariana Esteves de Oliveira ${ }^{1}$
}

\section{RESUMO}

Neste artigo, apresentamos parte da pesquisa realizada em nível de doutorado acerca da história da precarização do trabalho docente na SEE-SP. À luz da História Social do Trabalho, investigamos as categorias de salários, jornadas e contratos e aqui destacamos as formas pelas quais a flexibilização contratual, engendrada pela SEE-SP, construiu um ambiente de insegurança e instabilidade que pode ser sentida não apenas pelo (grande) número de professores com contratos temporários, mas inclusive por professores efetivos e estáveis, expressas em seus sentimentos acerca das atribuições anuais de aula e das constantes mudanças nas normas que regem à docência. Esperamos, com isso, contribuir na compreensão de processos gerais que concorrem para a desestabilização da classe trabalhadora no atual estágio do capitalismo, defendendo a presença do professor como sujeito do trabalho para a historiografia e para a luta por sua emancipação.

PALAVRAS-CHAVE: Precarização - Contratos docentes - Instabilidade.

\begin{abstract}
In this article, we present part of the research conducted at the doctoral level about the history of casualization of teaching in SEE-SP. From the perspective of social work history, we investigate the categories of wages, hours and contracts, and here we highlight the ways in which the contractual flexibility engendered by SEE-SP, built an environment of insecurity and instability that can be felt not only by the (large ) number of teachers with temporary contracts, but even by effective and stable teachers, expressed their feelings about the annual class assignments and constant changes in the rules governing the teaching profession. We hope, therefore, contribute to the understanding of general processes that contribute to the destabilization of the working class at the present stage of capitalism, defending the presence of the teacher as subject of work to historiography and the struggle for their emancipation.
\end{abstract}

KEYWORDS: Insecurity - Contracts teachers - Instability. 


\section{INTRODUÇÃO}

$\mathrm{Na}$ tese de doutorado intitulada "Professor, você trabalha ou só dá aula?: O fazer-se docente entre História, Trabalho e Precarização na SEE-SP”, defendida no Programa de Pós-Graduação em História da UFGD em 2016, apresentamos os resultados da pesquisa acerca do processo de precarização do trabalho docente na Secretaria Estadual de Educação de São Paulo - SEE-SP. Nossa investigação, à luz da História Social do Trabalho, objetivou descortinar o precário cenário material e subjetivo que se engendrou nos últimos sessenta anos no trabalho docente e que se tornou mais agressivo, e, portanto, mais precário, a partir dos anos 1990, com os efeitos da crise estrutural do capital, sua reestruturação produtiva aos moldes do toyotismo e a adesão às políticas neoliberais. Além disto, buscamos uma reflexão teórica que apontasse a ausência do professor como sujeito do trabalho na historiografia e defendemos o alargamento das perspectivas teórico-metodológicas da História Social do Trabalho para que outros sujeitos, além do operário como tipo ideal, ocupem espaços da produção do conhecimento histórico neste campo.

Para tanto, recortamos o objeto da pesquisa de modo a produzir exequibilidade empírica. Escolhemos a Diretoria Regional de Ensino de Andradina - SP, neste mesmo município, atingindo 128 professores em atividade ${ }^{2}$ e três professores aposentados. O primeiro grupo recebeu um questionário de cerca de cem questões objetivas e abertas que enfatizavam o processo nos últimos anos, uma vez que os professores entrevistados estão há menos de trinta anos em atividade, na sua grande maioria. No segundo grupo, os aposentados foram entrevistados oralmente, aos moldes metodológicos da História Oral (MEIHY, 1996; PORTELI, 1997), e desvelaram memórias que nos remeteram às gêneses da precarização do trabalho docente, pois suas carreiras na SEE-SP tiveram início entre os anos 1950 e 1960, conferindo, assim, profundidade temporal e subjetiva à pesquisa.

No que tange ao cenário material, observamos dois grupos de categorias. $\mathrm{O}$ primeiro, denominamos de tripé histórico, com as categorias de salários, jornadas e contratos, pois entendemos que tais elementos participam do processo histórico da precarização do trabalho docente desde o seu início. Na sequência, observamos as interfaces atuais que se relacionam com a precarização a partir dos anos 1990, outro grupo de categorias, como a cultura avaliacionista, que instituiu a bonificação por resultados, e as consequências do processo, como adoecimento, situações de violência e crise de mobilização da categoria. $\mathrm{O}$ cenário material que se desvelou foi um quadro de crise e denúncia e que foi melhor compreendido quando somado aos aspectos subjetivos que também mergulhamos, dando 
destaque aos processos de feminização, idealização e romantização da docência, fatores que agravam sobremaneira as condições de trabalho da categoria.

No presente texto, apresentaremos o processo a partir da flexibilização contratual operada na SEE-SP, pois, juntamente com a desvalorização salarial e com o aumento das jornadas docentes, este elemento constitui-se como instrumento material da precarização do trabalho docente de forma determinante, não apenas por ser histórico, mas por ser gerador do sentimento de insegurança e instabilidade que marca profundamente o trabalho nos tempos atuais. Faz-se mister conhecer os fatores e processos que engendraram as situações vividas pela classe trabalhadora no atual estágio do capitalismo, ainda que muitas vezes nem os próprios professores se reconheçam como parte da classe trabalhadora. A defesa por inserir a categoria docente nos estudos da historiografia do trabalho tem, neste sentido, uma vontade militante de clamar a unidade da classe operária em prol de sua emancipação.

\subsection{Trajetórias da flexibilização contratual dos trabalhadores docentes na SEE}

Concordamos com Orlando Jóia, quando este afirma que a questão dos contratos precários de trabalho, materializada no expressivo número de professores não-efetivos, juntamente com a questão salarial e a problemática das jornadas, compõem um tripé determinante para a compreensão da precarização do trabalho docente na SEE-SP:

\footnotetext{
O professor não concursado ou ACT [...] tem sido sempre maioria, salvo em breves períodos após os concursos. Submetidos à burocracia que os distribui pelas escolas, são eles que mais têm dificuldades de se impor profissionalmente. As reivindicações históricas dos professores revelam que o contrato temporário, ao lado da definição da jornada e dos salários, constitui o ponto crítico na constituição dessa categoria profissional. (JÓIA, 1993, s/p).
}

Assim como os demais elementos que elencamos desse cenário, a flexibilização contratual não é um fenômeno recente na Secretaria, embora as últimas décadas tenham sido de recrudescimento nessa direção. Antes mesmo dos primeiros estatutos do magistério paulista, a contratação de professores sem concurso público para atuação na secretaria estadual estava regulamentada por atos e decretos que se sobrepunham e se dispunham a ordenar as contratações docentes sem concursos, denominadas de "contratos a títulos precários". 
No bojo da progressiva expansão da oferta de ensino, em 1960, o Ato ${ }^{\circ} 47$ de 10 de novembro considerava prerrogativas e normatizações de contratação de "pessoal variável" para ministrar aulas "extraordinárias". Em 1963, o Decreto 41.982, de 03 de junho admitia a necessidade de "pessoal extranumerário" por tempo determinado, em caráter mensalista. No mesmo viés seguiram duas novas leis também em forma de decretos ${ }^{3}$, datados de 1968, que discorriam sobre as formas de admissão de docentes temporários. Ambos os decretos foram intensamente criticados por retirarem muitos direitos dos trabalhadores e, então, substituídos pelo Decreto 49.532/68 que, de acordo com Maria Isaura Cação, mantinha os contratos precários como legais, previa a dispensa sumária a critério da administração quando as vagas fossem objeto de concurso, mas "assegurava a retribuição de férias anuais de 30 dias, nojo (luto), gala (licença casamento), licença para tratamento de saúde e à gestante, porém, nenhum outro direito ou vantagem ao servidor contratado a título precário" (CAÇÃO, 2001, p. 41).

Apesar das sobreposições legais dos anos 1960, a lei mais decisiva nesta seara foi instituída em 1974 e esteve em vigor até a última década, quando o governo de José Serra no Estado de São Paulo implementou as leis no 1010, de 2007 e no 1093 de 2009, criando novas categorias de professores em função dos contratos flexíveis.

A Lei 500/1974 é sem dúvida um marco na concretização de um quadro de precarização contratual cujo número de professores não-concursados se aproximou, sazonalmente, do número de professores efetivos. Ela dispôs sobre a admissão e atribuição de aulas dos docentes denominados Ocupantes de Função-Atividade (OFA), também conhecidos como Admitidos em Caráter Temporário (ACT), termos que se cristalizaram no cotidiano docente. Conforme Cação (2001b), esses termos substituíram, inclusive, a palavra "contratação" que, por motivos legais, desaparecera da legislação nos anos 1970 e jamais retornou para configurar a admissão de professores sem concurso.

Durante mais de três décadas, esta lei regeu a admissão de professores sem concurso público, por meio de inscrição classificatória anual nas Delegacias de Ensino Regionais. Ainda hoje a lei não está revogada, sua redação possui atualmente 65 (sessenta e cinco) alterações por atos, decretos, despachos, leis complementares que se seguiram entre 1975 e 2009, mas as recentes reformas legais se sobrepuseram diminuindo sua importância em função da criação de novas categoriais contratuais.

Pelo tempo em que a lei vigorou com prioridade na regência da admissão e atribuição de aulas na SEE-SP, sua marca jurídica foi a ambiguidade, pois os docentes não eram considerados funcionários públicos estatutários, mas também não estavam sob a égide 
da CLT. Sua redação versou a partir de uma lógica que buscou instituir um regime peculiar onde "docentes ficam sujeitos ao regime instituído por esta lei, aplicando-se-lhes, excepcionalmente, quanto a admissão, seleção, jornada de trabalho, retribuição, férias e dispensa, as normas a serem expedidas por decreto, mediante proposta da Secretaria da Educação (SÃO PAULO, Lei 500/1974, Artigo 42). Desde sua promulgação houve críticas por parte dos trabalhadores organizados que viram no dispositivo a inconstitucionalidade contratual, além da importante questão da instabilidade, que se consolidou como marca do trabalho docente na SEE-SP. Com ela professores mantiveram-se sem perspectiva de estabilidade. Conforme o Artigo 35 da lei, eles poderiam ser demitidos imediatamente:

II - no caso de criação do cargo correspondente, a partir da data do exercício de seu titular; III - a critério da Administração, independentemente da criação do cargo correspondente, no caso da cessação da necessidade do serviço; IV - quando o servidor não corresponder ou incorrer em responsabilidade disciplinar (SÃO PAULO, Lei 500/1974).

Sendo a lei promulgada em 1974, o ano seguinte seria de mudança e adaptação. No início de 1975 a Secretaria divulgou (como fez e ainda faz anualmente), as regras da atribuição de aulas, pela Resolução nº1/1975, e o Decreto $\mathrm{n}^{\circ} 5.485 / 75$ para regulamentar dispositivos da Lei 500/74. Com eles, a interpretação de que os professores seriam contratados em caráter temporário até o provimento de vagas em concurso ganhou outra dimensão, a de que os professores seriam admitidos para aulas que "sobrassem" anualmente após a atribuição das aulas aos efetivos.

Ainda de acordo com Cação (2001), a execução da lei preconizou que fosse dado o maior número possível de aulas a um único professor, de forma que enquanto os melhores classificados (por serem efetivos e por tempo de serviço) completavam a carga máxima de aulas, os professores piores classificados ficavam com poucas (ou sem) aulas. A APEOESP reagiu à regulamentação da lei entendendo-a e a criticando como um elemento desagregador, que estimulava a fragmentação e a competição interna na categoria. No documento APEOESP Notícias de março de 1975, a entidade, sobre a Lei 500/74 e o Decreto que a regulamentou, afirmou que "Ao regulamentá-la, a Secretaria da Educação transformou-a num pesadelo para os mestres paulistas, lançando a discórdia entre os mestres, transformando-os em 'lobo que devora lobo"” (APEOESP, 1975, p.13).

Os professores aposentados entrevistados em nossa pesquisa, por terem ingressado na Secretaria antes de 1974, parecem não ter sofrido as consequências da lei. No 
entanto, vale destacar aqui que nenhum deles iniciou a carreira como professor efetivo, confirmando que a SEE-SP possui longa tradição na diversidade de contratos docentes. No caso da professora Maria do Carmo, que ingressou na SEE-SP em 1952, sua nomeação foi possível face aos pontos obtidos em um ano de trabalho em uma escola municipal rural. A professora se formou em 1950 e iniciou sua carreira na sequência. Na época, os pontos migravam e contavam para o ingresso na Secretaria Estadual, como nos lembrou a professora, "fiquei um ano nessa escola que chamava Escola Mista da Fazenda Figueira. Foi muito bom trabalhar lá. Trabalhei com aquelas crianças, e depois, no final do ano, eu entrei em concurso de remoção, não, de ingresso, que foi em 52. Aí já passei pro Estado”. Seu processo de efetivação foi mais rápido que dos demais entrevistados.

A professora Marisa, ingressante na rede em 1962, teve os três primeiros anos de carreira como docente substituta. Ela somente se efetivou após um concurso em 1965. O professor Benedito, que ingressou no Estado em 1964, só obteve sua efetivação por meio da aprovação de um concurso em 1972, atuando por oito anos em contrato de temporário. Todavia, é compreensível que, por terem ingressado antes de entrar em vigor, não tenham rememorado a lei de 1974 como marcante, ou como afirmou a APEOESP, como baliza da fragmentação não apenas contratual, mas separadora da categoria em ampla dimensão.

Durante mais de trinta anos esse foi o sentimento que rondou a identidade dos professores da SEE-SP, fragmentação, instabilidade, competição. Havia uma grande divisão entre efetivos e OFA, embora essas não fossem as únicas subcategorias de classificação docente $^{4}$. Sob o ponto de vista da forma de admissão e contrato, os professores na educação pública estadual paulista eram basicamente divididos em efetivos titulares de cargo e OFA regidos pela Lei 500/74.

Mas além deles, em número menor, existia o grupo de professores que, em virtude de ações judiciais acerca dos confusos contratos anteriores à Lei 500/74, haviam conquistado o direito de contrato pela CLT. Havia também os professores estáveis ${ }^{5}$ e ainda os "eventuais", grupo geralmente composto por estudantes ou profissionais de outras áreas que não se inscreveram e não se classificaram no processo anual nas DRE e eram catalogados para emergências (substituições esporádicas sobre faltas ou licenças curtas docentes), e os professores readaptados, classificação obtida por meio de processos internos que comprovam que o professor desenvolvera doença impeditiva da prática docente (em sala de aula) levandoo a readaptação, dentro da escola, em funções de apoio que pudesse realizar (SANTOS, 2012, p. 79). 
As condições de diferenciação de estatutos, contratos e formas de admissão na SEE-SP se cristalizaram e pioraram com o agravamento quantitativo do número de professores não concursados. Durante todo o tempo em que vigorou a lei 500/74, o número de professores efetivos era geralmente igual ou até menor que o número de docentes contratados temporariamente, com oscilações importantes apenas em períodos após os parcos concursos públicos. Durante décadas, os sindicatos apontaram para esse problema com insistência, colocando na pauta de reivindicações os concursos públicos e a assimilação de direitos por parte de professores OFA. O Ministério do Trabalho efetuou um estudo acerca das modalidades de contrato nas redes públicas em São Paulo e, sobre a SEE-SP, constatou:

\begin{abstract}
Existem professores temporários lecionando nas escolas estaduais há dezenas de anos. Em 2006, cerca de metade dos quase 249 mil funcionários ativos do Quadro de Magistério eram temporários, os chamados OFAs (ocupantes de função atividade), anteriormente chamados de ACT (admitidos em caráter temporário). Seu vínculo com o Estado é regido por uma lei que já tem mais de 35 anos, a Lei estadual 500, de 1974 (...)São várias as diferenças no emprego entre professores efetivos e OFAs, entre as quais destacamos: A estabilidade: só os professores efetivos têm estabilidade. O modo de ingresso na profissão: enquanto os efetivos são submetidos a concursos públicos de provas e títulos, os OFAs passam apenas por um processo de seleção. A atribuição das aulas: a cada ano há um processo de atribuição de aula entre os professores do Quadro do Magistério (efetivos e OFAs). Os efetivos têm prioridades de escolha e os OFAs ficam com as vagas restantes (...) Essas diferenças de estatuto entre professores da rede pública criam várias situações constrangedoras: os professores temporários se sentem muitas vezes discriminados pelos efetivos (BRASIL, 2009, p. 22-23)
\end{abstract}

Mas esse quadro, embora considerado problemático, piorou sobremaneira com as reformas operadas mais de trinta anos depois da lei, no governo José Serra (2007-2010), no âmbito da admissão e classificação docente na SEE-SP. Por meio das leis no 1010/07 (que criou a "São Paulo Previdência" - SPPREV) e no 1093/09 (Que dispôs sobre a contratação por tempo determinado no serviço público paulista) foram estabelecidos novos critérios de admissão de professores sem concurso, resultando em um novo processo de cisão (e precarização) da categoria.

De forma articulada, as leis foram norteadoras para a implementação de mecanismos de precarização e controle, como as provas seletivas anuais para professores não concursados e a fragmentação dos docentes em categorias "A", "P", "F”, "L", "O”, "S", "V" e "R", tendo como base o dia 02 de julho de 2007. Os professores "A" são os efetivos titulares de cargo, os professores "P" são aqueles que já haviam conquistado estabilidade pela Constituição Federal de 1988. As mudanças foram mais significativas aos professores OFA. $\mathrm{Na}$ prática, quem estava vinculado como OFA ao Estado nesse dia foi considerado estável, 
designado "Categoria F”. Quem não tinha vínculo nessa época, mas lecionou como OFA até o dia 16 de julho de 2009 foi considerado "Categoria L". Quem entrou no Estado como OFA depois de 17 de julho de 2009 foi considerado "Professor Contratado pela Lei 1093" dentro das categorias "O" (contrato anual), "S", "V" (substituto e eventuais). Os professores "R" são os readaptados por doença, ocupando funções fora de sala de aula na escola ${ }^{6}$.

A categoria "F" é a que mais "possui direitos" dentro dos não concursados. Esses professores precisam fazer provas anuais até que sejam aprovados (após isso a nota pode ser aproveitada no próximo ano). Caso não sejam aprovados, têm direito garantido de cumprir o mínimo de 12 horas semanais na escola, mas fora de sala (atividades de suporte). São professores considerados estáveis no quadro docente e são regidos pelo estatuto de 1985, incluídos no regime próprio de previdência dos servidores estatutários de São Paulo, atual SPPREV.

Para as categorias "L" (existente em maior número na transição entre 2007 e 2009) e “O” (após 2009) preconizou-se contratos pelo regime de previdência do INSS, e apenas para o período do ano letivo, sem registro em carteira ou FGTS e ainda tendo que cumprir um interstício de 200 dias entre o término de um contrato e a renovação de outro, conhecido como duzentena. Com a progressiva diminuição numérica dos professores "L", os professores "O" passaram a constituir o maior número do que poderíamos considerar de contratos precários. Os professores da categoria “O” são os admitidos em atribuições em contratos temporários de substituição aos professores afastados em licenças superiores a 15 dias, por prazo determinado até o fim do ano letivo, quando são demitidos.

Cumpre destacar que, embora as reformas citadas fossem justificadas como forma de legalizar uma situação historicamente incômoda (em que a Lei 500/74 fora interpretada e acusada pelos sindicatos como inconstitucional), as leis 1010/07 e 1093/09 não foram vistas de forma diferente. Ainda, mantiveram-se as contratações de professores eventuais (aulas por dia) e a categoria de professores readaptados persistiu clamando por isonomia de direitos.

As novas leis não resolveram o problema quantitativamente também. Os números que compõem o quadro de admissão docente na SEE-SP configuram um cenário alarmante. De acordo com Moura, já com a reforma consolidada em 2010, a quantidade de professores efetivos na SEE-SP era de 158.915, enquanto os professores não concursados (“O”, "L”, "F”, "V") somavam 120.012, ou seja, compunham $43 \%$ da totalidade do quadro do magistério, que era de 278.927 docentes. Dois anos depois, em 2012, o número total de docentes da rede estadual havia diminuído para 239.898 e, desse total, 48,7\% não eram concursados (MOURA, 2013, p.77). 
Em 2013, pelos dados do Cadastro Funcional da Educação do Estado de São Paulo, no item "classes docentes - totalização por categoria", o número total de professores da rede havia novamente diminuído, desta vez para o total de 233.192 professores, dentre os quais 117.762 são professores concursados titulares de cargo, ou seja, 50,5\%, enquanto os demais 115.430 docentes que atuam na rede pública paulista conformam os $49,5 \%$ de professores não concursados, distribuídos na "sopa de letrinhas" que a categoria ganhou após as reformas de 2007 e $2009^{7}$. Isso demonstra que o número de docentes temporários vem aumentando e que o número de professores totais do quadro da SEE-SP diminuiu, agravando a proporção, em que pese considerar que o número de matrículas discentes neste período também teve queda. Conforme dados do Censo Escolar, no item "Série Histórica", divulgado pela Coordenadoria de Informação, Monitoramento e Avaliação Educacional - CIMA/SEESP, que revelou que em 2010 a Rede Estadual possuía cerca de 4.526.382 matrículas nos níveis de ensino Infantil, Fundamental, Médio e Educação de Jovens e Adultos - EJA, e em 2013, este número caiu para 4.137.177 matrículas, nos mesmos níveis de ensino. Isso se dá, principalmente, em função do processo iniciado em meados dos anos 1990, mas ainda em curso, de transferência dos níveis de ensino Infantil e Fundamental I às secretarias municipais de educação. A crítica que se faz aqui está especialmente centrada no aumento da proporção de número de docentes temporários em relação ao total de docentes e número de docentes efetivos.

O que podemos inferir com esse emaranhado de reformas e classificações é a intensa instabilidade que caracteriza o trabalhador docente na SEE-SP. As recentes mudanças não deram conta de melhorar o quadro, aliás, pioraram as condições e não se sustentaram em diversos aspectos, produzindo uma avalanche de mini-alterações posteriores. É o caso da chamada "duzentena", pois ao preconizar que professores categoria "O" cumprissem interstício de 200 dias após o término do contrato, a rede ficou sem professores suficientes para a demanda (além de desempregar milhares de trabalhadores), de modo que a norma foi alterada em 2013 derrubando temporariamente (apenas para aquele ano) a exigência do prazo de interstício ${ }^{8}$, e diminuindo para 40 dias (quarentena).

Parece-nos humanamente impossível acompanhar as constantes mudanças operadas na Secretaria pela sobreposição de atos e decretos que impõem ou (des)impõem normas. Além da instabilidade em relação ao próprio emprego, os docentes se sentem perdidos quanto aos direitos relativos ao seu tipo de contrato. Os professores têm dúvidas frequentes sobre a legislação e por isso abrem canais de comunicação em redes sociais para 
compartilhar angústias e questionamentos. Neste aspecto, a comunicação e engajamento em rede torna-se instrumento para amenizar os efeitos da instabilidade.

Muitas vezes, um professor mais próximo à Diretoria de Ensino de sua região tem informações que ajudam outros professores que expõem suas dúvidas nas redes sociais. Também por isso passamos a acompanhar informalmente alguns diálogos docentes na página denominada "Grupo APEOESP" (não oficial) na rede social Facebook, cuja adesão já ultrapassou o número de 40.000 pessoas. Apesar de não trazermos tais desabafos para a apreciação do leitor desta tese (em virtude da dificuldade de amparar legalmente a publicação dos depoimentos dos diversos professores das mais diversas localidades do Estado), vale destacar ser notável que, dentre as intensas publicações diárias de professores sobre dúvidas e sobre suas angústias, grande parte seja referente às normas que regem contratações temporárias, seja da Categoria “O”, seja de professores eventuais que substituem docentes quando faltam.

Há dúvidas sempre que ocorrem mudanças legais ou pronunciamentos da Secretaria. Por exemplo, quando a SEE-SP anuncia um reajuste, muitos professores questionam se o direito será estendido à categoria "O" e aos eventuais, ou de como poderiam averiguar as diferenças nas prerrogativas de direitos em relação ao número de faltas abonadas anuais de cada categoria ${ }^{9}$, atendimento médico pelo IAMSPE $^{10}$, licenças, entre outros elementos que explicitam as divergências jurídicas nas fragmentadas categorias de contrato dentro da gama de professores da SEE-SP. São centenas de dúvidas e questionamento por dia onde podemos constatar ainda que a falta de clareza nas informações oficiais contribui com o sentimento de instabilidade. Foi naquele ambiente virtual que descobrimos, por exemplo, por meio de um drama pessoal vivido e compartilhado, que os professores categoria $\mathrm{O}$ não têm direito à licença paternidade de cinco dias conforme muitos estatutos orientados pela Constituição federal e CLT. Não têm direito a nem, sequer, um dia para este fimm ${ }^{11}$

Ainda, nos depoimentos virtuais, estas dúvidas são, geralmente, acompanhadas de insegurança e frustração. Cabe frisar que nem todas as postagens da página se destinam a questionamentos sobre normas para os professores não concursados, mas todas carregam as incertezas que marcam a fragmentação da categoria em tantas subclassificações. Conhecendo minimamente o emaranhado das leis e normas contratuais e passando os olhos nos depoimentos virtuais do referido grupo em rede, podemos compreender que, se houve intencionalidade de fragmentar a própria categoria docente por parte da SEE-SP nas diversas e sobrepostas subclassificações, o que aventamos como verdadeiro, os objetivos foram alcançados, pois o cenário que se coloca para o trabalhador docente não concursado na rede 
estadual paulista está embrulhado de cisões objetivas e subjetivas, composto pela incerteza e pelo sentimento de competição interna, sobressalente não apenas nos dias de atribuições de aulas, onde essa concorrência é mais agressiva e objetiva, mas também na rotina escolar.

\subsection{Instabilidade para além dos contratos: as faces atuais da flexibilização}

Segundo dados do DRHU (Departamento de Recursos Humanos) de 2013, na Diretoria Regional de Ensino de Andradina, em suas 23 escolas, dos 1017 professores, $52,21 \%$ (531) são efetivos titulares de cargo e 481 docentes não são concursados, estando contratados sob o regime de substituição, sendo 292 professores Categoria F e 189 Categoria O, além de cinco professores com estabilidade garantida na Constituição de 1988, denominados "estáveis" ou categoria P. A proporção de professores efetivos e não efetivos não destoa do quadro estadual atual. Vamos analisar, agora, como isso se configura atualmente na cidade de Andradina:

\section{Gráfico 1: Sobre Contratos: Professores Estaduais de Londrina.}

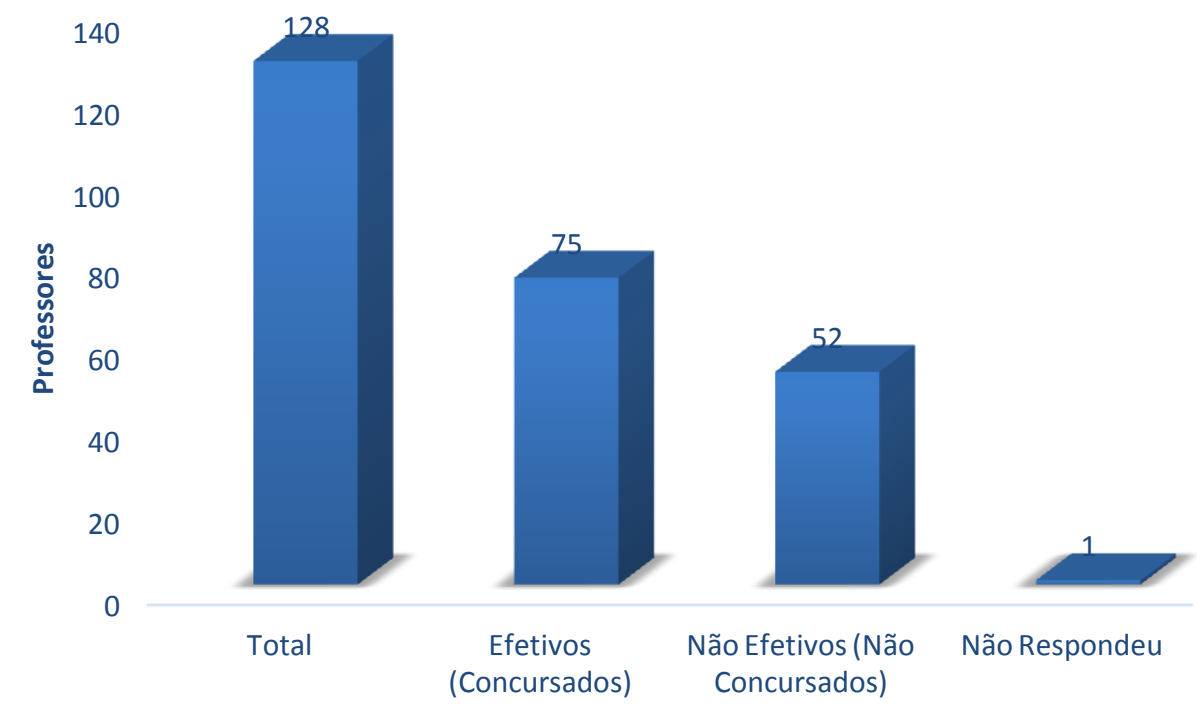

Gráfico 1: Sobre Contratos: Professores Estaduais de Londrina. Fonte: Elaboração Própria, São Paulo, 2017.

Como se vê pelo gráfico obtido com as respostas docentes, em Andradina há, atualmente, um sensível aumento de professores efetivos em relação ao número de 
professores não concursados, na comparação com a média estadual anteriormente discutida. Dos 128 docentes, 75 são concursados efetivos titulares de cargos $(58,5 \%)$ e 52 estão sob contratos em regimes diferenciados por não serem concursados $(40,6 \%)$, e um professor não respondeu sobre sua situação contratual. Os elementos que contribuem para isso podem ser diversos, mas dois se destacam. O primeiro deles reside na proximidade da data do último concurso realizado pela Secretaria, em novembro de 2013. Historicamente, os primeiros anos subsequentes aos concursos públicos sugerem um aparente processo de recomposição do quadro de professores efetivos. No entanto, as experiências demostram que esse processo não acompanha proporcionalmente o ritmo de aposentadorias e vacâncias de cargos, de modo que o déficit de docentes efetivos aumenta em poucos anos (JOIA, 1993).

Além disso, nos últimos anos, o processo de atribuição de aulas, regido por portarias lançadas anualmente antes das (e para as) inscrições, tem preconizado que os docentes efetivos atribuam suas aulas com prioridade, e os docentes não concursados são impelidos a pegar as aulas que sobram. Por meio dos questionários, observamos que um problema consequente disso é a necessidade de assumir aulas em escolas de municípios vizinhos, também regidas pela DRE de Andradina (são onze municípios abarcados pela regional). Ou seja, os professores efetivos, melhor classificados, atribuem suas aulas em escolas cuja proximidade e turno sejam os melhores possíveis, às vezes esgotando as aulas na cidade onde residem, e com isso professores com pior classificação podem ter que lecionar em outros municípios, que apresentem carência de professores.

É o que nos relatou, por exemplo, a professora da Categoria $\mathrm{F}$ ao afirmar, como problema referente ao seu tipo de contrato: "Lecionar onde há aulas, mesmo quando o salário não compensa. As atribuições são primeiramente para os efetivos, portanto o que sobrar, o resto. E também há atribuições que são compulsórias” (Questionário 26). Na mesma direção, outra professora discorre que o problema do seu tipo de contrato (Categoria F) é "a atribuição de aulas, e quando não tem aulas, tem que ir para outras cidades" (Questionário 53). Evidentemente, em algum momento da carreira destas professoras, elas passaram por tais experiências ou assistiram aos seus colegas nestas condições. Com isso, podemos inferir ainda que, no momento da aplicação da pesquisa, pode haver uma parcela de professores estaduais de Andradina, não concursados, lecionando em cidades próximas por não terem conseguido atribuir aulas no município.

E ainda que esta possibilidade não altere concretamente o gráfico obtido, já que nossa pesquisa se limitou às escolas estaduais do município, ela serve para relativizarmos o otimismo que se coloca em função da diferença na proporção entre efetivos e não efetivos 
que, em Andradina, parece maior que no quadro geral estadual. O mesmo ocorre quando supomos a ausência de professores da categoria $\mathrm{O}$ que não participaram da pesquisa nas escolas por estarem cumprindo a chamada Duzentena (ou em Quarentena), interstício obrigatório entre contratos.

Ademais, mesmo menor na proporção, o número de professores não efetivos é expressivo dentro de uma perspectiva do ideal. Mais de $40 \%$ dos docentes em exercício nas escolas estaduais de Andradina não são concursados. A instabilidade e a fragmentação dentro da categoria são consequências gerais e evidentes, mas há ainda outros reflexos revelados pelos professores da pesquisa e que merecem nossa atenção.

No geral, os professores de categoria F (29 docentes) versaram sobre os problemas relativos à insegurança em relação ao número e locais de aulas que lhes são atribuídas compulsoriamente em função do tipo de contrato ${ }^{12}$. Lembramos aqui que esta categoria docente ganhou estabilidade quanto ao vínculo do emprego junto à SEE-SP sob a condição de lecionar um mínimo de aulas (12) disponibilizadas sob as necessidades da Secretaria. Como vimos, nem todos conseguem assumir as aulas nas escolas próximas, na cidade onde residem, e pior, nem todos conseguem completar a carga ou atingir o número de aulas de que necessitam para se manter, como é o caso da docente, Categoria F, que relatou: "Este ano já estamos no mês de maio e até agora só consegui pegar 15 aulas, sendo que a carga horária é 32” (Questionário 76). Isto é, para além da instabilidade e da insegurança, a questão contratual interfere na subsistência (material) desses sujeitos.

Chama atenção, também, o tempo de carreira dos professores desta categoria. Pelos dados, confirmamos que ser professor temporário na SEE-SP nem sempre é uma condição temporária. Os professores que hoje são Categoria $\mathrm{F}$ iniciaram suas carreiras na SEE-SP pela Lei 500/74 (e estavam atuando em 2007 para converterem-se à referida categoria). Muitos deles estão na rede estadual há décadas e tudo indica que vão se aposentar sem obter a efetivação. O caso mais emblemático é da professora que informou ter ingressado na SEE-SP em 1979. São 36 anos de atividade docente na instituição, e a professora só completará a idade mínima para aposentadoria integral ao final de 2015 (Questionário 73). Há outros casos de professores com 20 anos ou mais de trabalho na SEE-SP, como os professores que ingressaram na condição de OFA entre 1983 e 1995 (16 entrevistados). Todos estes se mantêm, ainda hoje, como professores não titulares de cargos na SEE-SP, marcados principalmente pela insegurança.

Assim como os professores aposentados, os professores efetivos ativos, em sua maioria, já estiveram nessas condições e não por pouco tempo. Calculamos uma média de 
tempo, em anos, que os docentes efetivos trabalharam como OFA ou Categorias F e O, antes de passarem no concurso e se tornarem efetivos. Em média, os professores trabalharam por 7,4 anos como contratados temporariamente ${ }^{13}$. Consideramos essa média como alta e entendemos que a questão dos contratos precários atingiu de maneira concreta o corpo docente das escolas estaduais de Andradina inclusive quando se trata dos professores, hoje, efetivos. Alguns desses docentes passaram mais de 20 anos nestas condições antes de conseguirem a aprovação em concurso público. A professora do Questionário 108, efetivada em 2013, trabalhou 25 anos em caráter precário, e o professor do Questionário 48 ingressou na SEE-SP como OFA em 1991 e se efetivou em 2014, após 23 anos. Uma docente concursada lembrou sua condição de contratada temporariamente e relatou: "Já fui Categoria O e quando prestei o concurso fiz a opinião: se não passar no concurso desisto do Estado" (Questionário 98).

Em pior situação encontram-se os docentes que atualmente são Categoria O. Em nossa pesquisa, 23 professores informaram pertencer a esse grupo contratual ao mesmo tempo que também informaram ser professores "eventuais", pois além do contrato temporário anual, aceitam substituir eventuais faltas e pequenas licenças docentes para somarem nos proventos. Eles revelaram, por meio do questionário, que os problemas decorrentes às suas situações contratuais permeiam as dificuldades na atribuição de aulas, caracterizada como processo de incertezas, como descreve a professora: "pouca informação de como e onde se candidatar (...) períodos de inscrição curtos" (Questionário 80). Nesta mesma direção está o depoimento da docente que afirma que, por ser Categoria $\mathrm{O}$, sua carreira é pautada nas "incertezas acerca do período de trabalho e contratação" (Questionário 12).

Também se destacam os relatos que mencionam problemas de acesso aos direitos (que os efetivos têm), como convênio médico, a redução no número de faltas abonadas e dias de folga por luto ou casamento. Nesse sentido, o professor do Questionário 15 elencou algumas situações que a Categoria O enfrenta: "Carga horária, atendimento médico, duzentena-quarentena". Outros docentes mencionaram a questão das quarentenas como centrais para pensar o sofrimento docente na categoria, como no relato da professora que desabafou lembrando que "fiquei de quarentena e sofri muito! Me senti inútil, sem trabalhar, sem condições financeiras. " (Questionário 81).

Uma professora ainda atentou ao fato de que como categoria $\mathrm{O}$, já sofreu, inclusive, "atrasos de salários devido ao tempo que foi contratado", pois apesar de informatizado, o sistema de pagamento da SEE-SP demora cerca de três a quatro meses para inserir os contratados temporariamente e suas alterações de carga horária (Questionário 81). 
Mas a grande maioria dos professores não efetivos mencionou que a maior dificuldade reside no processo de atribuição de aulas. A professora do Questionário 73 relatou que "na atribuição, no começo do ano, é sempre um transtorno, você nunca sabe se vai pegar aulas". Cientes disso, relacionamos estas questões referentes aos contratos com algumas perguntas relativas às condições de trabalho que concernem ao processo de atribuição de aulas (Questões 5.14, 5.14.1 e 5.14.2), onde questionamos se o período de atribuição de aulas e o tempo que o antecede representam momentos de tensão ao docente. A maioria consentiu, 115 professores informaram que a atribuição de aulas traz tensões e preocupações $(89,8 \%)$.

A atribuição de aulas é tensa até para professores efetivos, como é o caso da professora que afirmou que "o professor fica preocupado se irá completar ou não a jornada" (Questionário 58), ou ainda outra docente que informou que, mesmo efetiva, o processo de atribuição de aulas pode implicar em "mudança de horário e redução de aulas" (Questionário 70). Semelhante ao depoimento do professor que desabafou: "você nunca sabe se vai ter sala suficiente para todos" $" 14$ (Questionário 82). Outra professora concursada lembrou-se do mesmo problema, sentenciando que a "diminuição de classes acarreta menos aulas" (Questionário 88). Para estes docentes, também há insegurança, mesmo que estejam com seus contratos firmados sob estatuto e, portanto, possuírem estabilidade. A professora do questionário 102 relatou, sobre a tensão na atribuição, que tem "Há sempre insegurança, pois a legislação da atribuição sempre contém mudanças".

\section{CONSIDERAÇÕES POSSÍVEIS}

Evidentemente, são os professores contratados temporariamente aqueles que mais sofrem com a insegurança gerada no progressivo desmonte de direitos trabalhistas, no acesso às aulas e nas incessantes mudanças acarretadas pelo fato de que os processos de atribuições de aulas têm regimentos expedidos anualmente, além da iminente possibilidade de não haver aulas por falta de salas ou por impedimento jurídico em tempos de interstício contratual. Mas ao relacionarmos as inseguranças vividas por estes docentes com aquelas relatadas por professores concursados, nossa intenção foi observar que as flexibilizações alcançaram todos os níveis de contratos docentes da SEE-SP, toda a variedade de "letrinhas" rotuladas pelas diferentes formas de admissão. 
Não há dúvida que a fragmentação da categoria se institucionalizou, do ponto de vista contratual, e a efetivação, conquistada por alguns muitos anos depois do ingresso e, por outros nunca alcançada, parece ser um marco divisório, o alento e o horizonte de professores na busca da estabilidade que tem se constituído como vantagem única e isolada da carreira (como veremos adiante). Assim, a instabilidade docente parece marcada pela frustração e pelo desejo de efetivação, fazendo com que os professores não-efetivos, ainda que trabalhando nas precárias condições onde também estão os professores efetivos, almejem, como horizonte melhor, estarem na condição de professores efetivos (como se esta fosse ideal). Mas no bojo das lutas por concursos públicos, outros entraves se apresentam. Por exemplo, professores que trabalham como categoria $\mathrm{O}$ na SEE-SP por vários anos e, quando são aprovados em concurso público para a sonhada efetivação, esbarram em situações quase bizarras que os impedem, como a reprovação em exames médicos admissionais.

Exemplos foram destaques na mídia recentemente. Segundo reportagem do Jornal Folha de São Paulo, de 17 de maio de 2014, foram diversas as ocorrências de reprovação de professores candidatos nos exames médicos admissionais nos últimos concursos públicos da SEE-SP por estarem acima do peso permitido, considerados obesos ${ }^{15}$. Na maioria dos casos, os docentes entraram com processos judiciais e, por meio de liminares, a justiça assegurou a posse de muitos trabalhadores na mesma situação. Grande parte desses professores, inclusive, para tentar garantir o cargo, nesse ínterim, emagreceu para alcançar os índices de massa corporal exigidos para admissão. Nas postagens referentes ao tema na página virtual que analisamos, o sentimento de indignação se expressa em depoimentos lembrando que a maioria dos professores reprovados por obesidade já são docentes em atuação na rede pública por meio dos contratos temporários há anos. As contradições são explicitadas no fato dos professores obesos serem aceitos enquanto temporários (destituídos de direitos, inclusive no acesso de serviço público de saúde pelo IAMSPE) e renegados quando conquistariam a estabilidade e inclusive o direito a esse serviço. Apesar de não encontrarmos um caso congênere entre os docentes em Andradina, compreendemos que situações como esta são emblemáticas para caracterizar a precarização do trabalho na SEE-SP.

Tais situações revelam, por fim, a fragilidade das condições dos trabalhadores, escancaram um cenário tão precário e desestabilizador que fica difícil vislumbrar qualidade no trabalho docente (sem que haja um hercúleo esforço por parte dos professores) e, consequentemente, da educação ofertada na rede pública. Sofrem os professores e os alunos. O cenário está composto, portanto, de docentes mal remunerados, que trabalham muito, durante muitas horas em diferentes turnos e jornadas, sem tempo para preparar aulas e corrigir 
as atividades, fragmentados por uma diversidade de tipos de contratos que os colocam uns contra os outros, e caracterizados pela instabilidade e pela insegurança.

\section{REFERÊNCIAS}

CAÇÃO, Maria Izaura. Jornada de trabalho docente: delineamento histórico da organização do trabalho do magistério público estadual paulista. Tese (Doutorado em Educação). Campinas, Universidade Estadual de Campinas, 2001.

. Recuperando a memória: organização do trabalho do magistério público estadual paulista - 1933/1990. Org \& Demo (Marília), Marília, v. 2, n. n. 1, p. 73-86, 2001 (b).

JÓIA, Orlando (coord.). APEOESP dez anos - 1978/1988. Memória do movimento dos professores do ensino estadual paulista. São Paulo: CEDI - Centro Ecumênico de Documentação e Informação, 1993. (mimeogr.)

MOURA, Carolina Baruel de. A precarização do trabalho docente nas escolas estaduais paulistas. Dissertação. (Mestrado em Educação) - Universidade Estadual Paulista, Faculdade de Filosofia e Ciências, Marília, UNESP, 2013.

MEIHY, José Carlos Sebe Bom. Manual de História Oral. São Paulo: Loyola, 1996

PORTELLI, Alessandro. O que faz a História Oral diferente. Projeto História - Revista do Programa de Estudos Pós-Graduados em História e do Departamento de História da PUC/SP. São Paulo, 1997.

SANTOS, Edson Segamarshi. A situação funcional dos professores da rede estadual paulista: problemas de admissão, seleção e dos concursos públicos (1976-2010). Tese (Doutorado em Educação). Pontifícia Universidade Católica de São Paulo. São Paulo, 2012. 


\section{FONTES:}

APEOESP. Manual do Professor, s/d.

APEOESP-CEPES. Caderno Conversas sobre a Carreira, 2012.

BRASIL. MEC/Inep/Deed - In MINISTÉRIO DA EDUCAÇÃO. Estudo exploratório sobre o professor brasileiro com base nos resultados do Censo Escolar da Educação Básica 2007 / Instituto Nacional de Estudos e Pesquisas Educacionais Anísio Teixeira. - Brasília : Inep, 2009.

ENTREVISTA. Benedito Newton Assuiti. (Digital). Produção: Mariana Esteves de Oliveira, Andradina, 2016, $18 \mathrm{~min}$.

ENTREVISTA. Maria do Carmo Melo Sanches. (Digital). Produção: Mariana Esteves de Oliveira, Andradina, 2016, $38 \mathrm{~min}$.

ENTREVISTA. Marisa Mariani Pardo. (Digital). Produção: Mariana Esteves de Oliveira, Andradina, 2016, 34 min.

SÃO PAULO- DRHU (Departamento de Recursos Humanos). Classes Docentes, 2013.

SÃO PAULO. Assembleia Legislativa do Estado de São Paulo. Lei Complementar n. 444, de 27 de dezembro de 1985. Dispõe sobre o Estatuto do Magistério Paulista e dá providências correlatas. Diário Oficial do Estado São Paulo, São Paulo. Disponível em: http://www.al.sp.gov.br/repositorio/legislacao/lei\%20complementar/1986/lei\%20complement ar\%20n.499,\%20de\%2029.12.1986. htm . Acesso em: 15 jan. 2014.

SÃO PAULO. Assembleia Legislativa do Estado de São Paulo. Lei n. 500/74, de 13 de novembro de 1974. Institui o regime jurídico dos servidores admitidos em caráter temporário e dá providências correlatas. Diário Oficial do Estado São Paulo, São Paulo. Disponível em: http://www.al.sp.gov.br/repositorio/legislacao/lei/1974/lei\%20n.500,\%20de\%2013.11.1974.ht m. Acesso em: 05/10/2013

Lei Complementar no 1215/13, que altera a Lei Complementar $n^{\circ}$ 1093/09. 
. Lei $\mathrm{n}^{\mathrm{o}} 11.125 / 02$, de 11 de abril de 2002 (IAMSP)

\footnotetext{
${ }^{1}$ Doutora em História pela UFGD; Professora Adjunta na Universidade Federal do Mato Grosso do Sul - UFMS, Campo Grande - MS. E-mail: mariana.esteves@ufms.br
}

2De um total de 200 docentes em média. Dados de 2012, extraídos de: Censo - IBGE, "Matrículas e Docentes”.

${ }^{3}$ Decretos 49.213/68 e 49.319/68.

${ }^{4}$ Outra importante divisão da categoria tem por base o tipo de ensino onde o professor ministra aulas, dividido em séries e/ou ciclos. Esta divisão leva em conta o cargo docente de concurso. Atualmente, existem três tipos de cargos docentes na SEE-SP, apesar da progressiva extinção de dois deles. São eles: O PEB I (Professor de Educação Básica I), que atua nas séries iniciais do Ensino Fundamental, do $1^{\circ}$ ao

$5^{\circ}$ ano, e deve ter habilitação em licenciatura, geralmente sendo Pedagogia, o PEB II (Professor de Educação Básica II), que atua nas séries finais do Ensino Fundamental, do $6^{\circ}$ ao $9^{\circ}$ ano e no Ensino Médio, e deve ter Licenciatura Plena específica à disciplina a ser ministrada, e ainda o Professor II, cujo cargo está em processo de extinção pois permitia a chamada Licenciatura Curta, hoje em desuso. Além disso, o PEB I também tem diminuído na SEE-SP após o processo de municipalização do ensino, de modo que o Ciclo Fundamental I está atualmente sob responsabilidade dos municípios paulistas. O número de professores PEB I ainda é significativo, pois apesar do nível de ensino ter sido transferido às escolas municipais, os docentes continuaram tendo seus cargos na SEE-SP por meio do convênio firmado entre Estado e Municípios, ficando "adidos" (ou emprestados) às secretarias municipais. A SEE-SP todavia não tem disponibilizado o cargo em concursos, o que nos permite inferir que ele será extinto quando o número atual de professores PEB I se exaurir por meio de aposentadoria e outros. Deste modo, numericamente, a partir dos dados do DRHU de 2013, aferimos que a SEE-SP tem 63.691 professores PEB I, 169.436 professores PEB II e 65 professores PROF II. Na DRE de Andradina nos seus onze municípios, são 158 PEB I, 857 PEB II e 2 PROF II. Cabe destacar que os cargos possuem remunerações diferentes, sob justificativa da complexidade do nível de ensino. Em 2013, o PEB I inicial, com 40 horas, recebia R\$ 1950,00 e o PEB II inicial com 40 horas recebia R\$ 2.257,00 (APEOESP, Tabela Salarial 2013). Por isso compreendemos a divisão de cargos como também uma forma de fragmentação da categoria. Na prática, os docentes lecionam nos dois níveis de ensino para compor jornada, gerando complexos "cálculos" nos holerites. Sobre a divisão da categoria por cargos, recomendamos a leitura de SANTOS, Edson Segamarshi. A situação funcional dos professores da rede estadual paulista: problemas de admissão, seleção e dos concursos públicos (1976-2010). Tese de Doutorado. Programa de Pós-Graduação em Educação: História Política e Sociedade. São Paulo, PUC, 2012.

${ }^{5}$ Com o advento da Constituição Federal de 1988, o Artigo 41 estabeleceu que funcionários que prestavam serviços em órgão públicos por cinco anos sem interrupção deveriam ser contemplados com estabilidade e impedidos de serem dispensados. Isso levou a uma subcategoria docente de "professores estáveis".

${ }^{6}$ Informações retiradas da publicação: APEOESP-CEPES. Caderno “Conversas sobre a Carreira”, 2012.

${ }^{7}$ Segundo o mesmo documento, dos 115.430 professores não concursados, 821 são professores "P" (estáveis pela Constituição de 1988), 02 são CLT (Ações judiciais anteriores), 60.710 são Categoria "F”, 53.893 são Categoria “O” e 04 professores são Categoria “L” (SÃO PAULO, Classes Docentes, 2013, s/p).

${ }^{8}$ Lei Complementar $n^{\circ} 1215 / 13$, que altera a Lei Complementar no 1093/09.

${ }^{9}$ Professores efetivos ou estáveis têm direito a seis dias de faltas abonadas por ano (LC 836/97), enquanto professores Cat. O podem "abonar" dois dias no ano (LC 1093/09). As faltas abonadas consistem em faltas que não serão descontadas dos proventos dos professores. De acordo com a Manual do Professor, elaborado pela APEOESP (2011), as ausências ao trabalho ou faltas são tipificadas como injustificadas, justificadas, abonadas ou falta médica. A falta injustificada, além do desconto salarial, interrompe o período aquisitivo da licença- 
prêmio. Para o docente não-efetivo, 15 faltas injustificadas seguidas ou 30 intercaladas podem resultar no mesmo procedimento. As faltas justificadas importam em desconto salarial, mas não sujeitam o servidor a processo administrativo por abandono de cargo ou função. As ausências justificáveis são aquelas cuja razoabilidade constitui escusa para o não comparecimento. As faltas abonadas são computadas para todos os fins e efeitos legais. Existe a possibilidade de 6 faltas abonadas por ano, observado o limite de uma por mês. A falta abonada é contada para todos os efeitos, inclusive sexta-parte e adicional quinquenal, bem como para classificação para o processo de atribuição de aulas, porém entra na contagem do limite das trinta faltas que o servidor pode ter para fins de bloco aquisitivo da licença-prêmio. Legislação: Artigo 110, § $1^{\circ}$ da Lei $n^{\circ} 10.261 / 68$ e artigo $20, \S 1^{\circ}$ da Lei ${ }^{\circ}$ 500/74; Decreto no $^{\circ}$ 39.931/95; Decreto ${ }^{\circ}$ 52.054/2007.

${ }^{10}$ Instituto de Assistência Médica ao Servidor Público Estadual. Não é extensivo aos contratados temporariamente.

${ }^{11}$ Estas informações e outras falas docentes contidas na página virtual contribuíram, de maneira indireta, para as leituras que embasaram as perguntas elaboradas nesta pesquisa, por isso não nos furtamos em mencionar que acompanhamos a rede social em busca de elementos e indícios em nossa pesquisa. Mas em virtude de limitações metodológicas acerca de como resguardarmos as implicações legais de tornarmos públicas as falas de pessoas cujo contato se dispersa na velocidade acelerada da rede social, não usaremos a página como fonte para citações. Cabe salientar, todavia, que o grupo virtual torna públicos muitos dos debates ali contidos, portanto, para melhor conhecer tais diálogos, recomendamos visitar o link: https://www.facebook.com/groups/APEOESP/

${ }^{12} \mathrm{O}$ Contrato dos professores Categoria F impõe que o docente tenha, no mínimo, 12 aulas atribuídas a ele. Estas aulas lhe são atribuídas, inclusive compulsoriamente, nos lugares e horários que sobrarem aulas, Conforme Artigo 1 das Disposições Transitórias da Lei 1093/2009.

${ }^{13} \mathrm{O}$ cálculo se deu entre os docentes que informaram os anos de ingresso e efetivação. Dentre os 75 docentes efetivos, 66 responderam à questão, permitindo esse cálculo.

${ }^{14} \mathrm{O}$ professor faz menção aqui do recorrente processo de fechamento de salas de aulas, anualmente, por iniciativa da SEE-SP, acarretando em superlotação das salas remanescentes e diminuição dos postos de trabalho docente. No último ano, para entrada do período letivo de 2015, o corte foi de mais de 3.000 salas de acordo com a APEOESP. É possível conferir alguns dados no link criado para atualizar o ranking de fechamento de salas, pelo sindicato, in http://www.APEOESP.org.br/noticias/noticias/placar-do-fechamento-superlotacao-de-classes/

${ }^{15}$ Conferir em http://www1.folha.uol.com.br/educacao/2014/05/1455960-pericia-barra-docente-obeso-emconcurso.shtml (Acesso em 12/07/2014).

RECEBIDO EM: Setembro de 2016

\section{APROVADO EM: Dezembro de 2016}

